\title{
Context predicts Word Order Processing in Broca's Region
}

Kristensen, Line Burholt; Engberg-Pedersen, Elisabeth; Wallentin, Mikkel

Published in:

Journal of Cognitive Neuroscience (Online)

DOI:

10.1162/jocn_a_00681

Publication date:

2014

Document version

Publisher's PDF, also known as Version of record

Citation for published version (APA):

Kristensen, L. B., Engberg-Pedersen, E., \& Wallentin, M. (2014). Context predicts Word Order Processing in Broca's Region. Journal of Cognitive Neuroscience (Online), 26(12), 2762-2777.

https://doi.org/10.1162/jocn_a_00681 


\title{
Context Predicts Word Order Processing in Broca's Region
}

\author{
Line Burholt Kristensen ${ }^{1,2}$, Elisabeth Engberg-Pedersen ${ }^{1}$, \\ and Mikkel Wallentin ${ }^{2,3}$
}

\begin{abstract}
The function of the left inferior frontal gyrus (L-IFG) is highly disputed. A number of language processing studies have linked the region to the processing of syntactical structure. Still, there is little agreement when it comes to defining why linguistic structures differ in their effects on the L-IFG. In a number of languages, the processing of object-initial sentences affects the L-IFG more than the processing of subject-initial ones, but frequency and distribution differences may act as confounding variables. Syntactically complex structures (like the objectinitial construction in Danish) are often less frequent and only viable in certain contexts. With this confound in mind, the L-IFG activation may be sensitive to other variables than a syntax manipulation on its own. The present fMRI study investigates the effect of a pragmatically appropriate context on the process-
\end{abstract}

\section{INTRODUCTION}

There is a number of reasons why She loves you is a more common sentence than You, she loves (26 solutions vs. 0 solutions according to a search in the British National Corpus). Even when disregarding references to a famous song by the Beatles, mentioning the Actor (the lover) before the Undergoer (the loved one) is the most frequent way of expressing this proposition. The subjectinitial version She loves you can occur in numerous contexts, whereas the object-initial version of the proposition is restricted to specific contexts. As an example, the object is licensed in first position if it is interpreted contrastively as in She likes George, Paul, John, and Ringo alright, but you, she loves. Here the persons referred to by means of George, Paul, Jobn, Ringo and you can be seen as a set of persons, one of which, namely the referent of you, is contrasted against the rest of the set (cf. the definition of contrast by Chafe, 1976). As well as exhibiting different frequency distributions and occurring in different contexts, object-initial and subject-initial versions of the same proposition are known to exhibit different processing patterns in a number of languages. In languages such as English, Finnish, German, Swedish, and Danish, object-

\footnotetext{
${ }^{1}$ University of Copenhagen, ${ }^{2}$ Aarhus University Hospital, ${ }^{3}$ Aarhus University
}

ing of subject-initial and object-initial clauses with the IFG as our ROI. We find that Danish object-initial clauses yield a higher BOLD response in L-IFG, but we also find an interaction between appropriateness of context and word order. This interaction overlaps with traditional syntax areas in the IFG. For object-initial clauses, the effect of an appropriate context is bigger than for subject-initial clauses. This result is supported by an acceptability study that shows that, given appropriate contexts, object-initial clauses are considered more appropriate than subject-initial clauses. The increased L-IFG activation for processing object-initial clauses without a supportive context may be interpreted as reflecting either reinterpretation or the recipients' failure to correctly predict word order from contextual cues.

initial clauses are associated with more processing difficulties than subject-initial clauses. Object-initial clauses are more frequently judged ungrammatical compared with subject-initial clauses (German: Bader \& Häussler, 2010; German: Bader \& Meng, 1999; Swedish: Hörberg, Koptjevskaja-Tamm, \& Kallioinen, 2013), they are more difficult to comprehend (German: Bornkessel, Schlesewsky, \& Friederici, 2003; English: Ferreira, 2003; Danish: Kristensen, Engberg-Pedersen, \& Poulsen, 2014), they read more slowly (Finnish: Hyönä \& Hujanen, 1997; Danish: Kristensen et al., 2014), and question RTs are slower (Danish: Kristensen et al., 2014).

\section{Word Order Processing and Neurological Measures}

The processing of object-initial clauses as compared with subject-initial clauses also affects neurological measures differently. In the EEG literature, object-initial clauses that are locally ambiguous between an object-initial and a subject-initial reading are known to elicit an N400 effect following processing of the disambiguating word (e.g., in Swedish: Hörberg et al., 2013). This N400 effect has been interpreted as driven by difficulties in the mapping of thematic roles to the argument noun phrases (BornkesselSchlesewsky \& Schlesewsky, 2009). Numerous neuroimaging experiments have identified the left inferior frontal gyrus 
(L-IFG), particularly BA 44/45, coinciding with the pars opercularis/pars triangularis, as being particularly sensitive to the difference between processing of subject-initial and object-initial clauses, with object-initial clauses showing a greater BOLD response than subject-initial ones (Grodzinsky \& Santi, 2008; Hagoort, 2005). Although there is general agreement that this area, also known as Broca's area, is central to word order processing, there is much debate as to why there is a greater BOLD response for object-initial clauses than for subject-initial clauses. The difference in activation has primarily been described as being due to syntactic movement (Kim et al., 2009; Grodzinsky \& Santi, 2008; Ben-Shachar, Palti, \& Grodzinsky, 2004), due to working memory demands (Fiebach, Schlesewsky, Lohmann, von Cramon, \& Friederici, 2005; Caplan \& Waters, 1999), and due to argument hierarchy violations (Bornkessel, Zysset, Friederici, von Cramon, \& Schlesewsky, 2005). Although some of these explanations see BA $44 / 45$ as specialized for language operations and others hold a domain-general position, they are all based on the idea that an operation or relation within a single clause results in the increased BOLD response for object-initial clauses. Whereas ERP studies have already for some years examined word order processing in connection with extrasentential factors (e.g., Cowles, Kluender, Kutas, \& Polinsky, 2007; Bornkessel \& Schlesewsky, 2006), neuroimaging studies have neglected such investigations, although Bornkessel-Schlesewsky, Grewe, and Schlesewsky (2012) have recently suggested that discourselevel factors may be responsible for differences found in previous sentence processing studies. The aim of the present study is to test whether intraclausal explanations are sufficient to explain the role of the L-IFG or would benefit from taking discourse-level factors into account.

\section{The Role of Extraclausal Factors}

In the present paper, we argue that the increased BOLD response for object-initial clauses cannot be fully understood with reference to intraclausal factors alone. Rather, extraclausal pragmatic factors must be taken into account. In our study, we take the processing of Danish objectinitial clauses as an example, but we expect that contextual effects on word order processing should not be limited to Danish.

Danish is yet another language with differences between subject-initial and object-initial clauses when it comes to frequency patterns, contextual patterns, and processing patterns. Object-initial clauses are associated with a lower corpus frequency (Kristensen, 2013; Thomsen \& Kristensen, in press), more specific contextual requirements (Erteschik-Shir, 2007), lower comprehension accuracy (Kristensen et al., 2014), longer reading time (Kristensen et al., 2014), and longer question RT (Kristensen et al., 2014). As for neurological measures, the processing of Danish object-initial clauses also exhibits a greater BOLD response than the processing of subject-initial clauses (Kristensen, Engberg-Pedersen, Nielsen, \& Wallentin, 2013).
All in all, object-initial clauses in Danish have an inferior status to subject-initial clauses when it comes to both frequency and ease of processing.

Danish is a V2 language (like e.g., German and Dutch). In V2 languages the finite verb of a declarative main clause always occurs in the second position of the clause. The first position can be occupied by a number of syntactic constituents of varying length, including subjects, as in (1), objects, as in (2), and adverbials. In the following two examples, the first position is underlined.

\section{(1) Hun bemærkede ham \\ She noticed him \\ 'She noticed him' \\ (2) Ham bemærkede hun \\ Him noticed she \\ 'Him, she noticed'}

For subject-initial clauses such as (1) there are fewer contextual requirements than for object-initial clauses such as (2). Object-initial clauses can occur in a limited set of contexts, for example, in contexts where the initial object is anaphoric and establishes a link to previous content (Hansen \& Heltoft, 2011; Harder \& Poulsen, 2001) or where the initial object expresses a contrast (Kristensen, 2013). If the initial object ham ('him') in (2) is contrasted with the alternatives of a set (e.g., other people present), it is licensed in first position in Danish. As mentioned previously, contrasted initial objects are also known in English, as in She likes George, Paul, John, and Ringo alright, but you, she loves. As in English, a contrasted object in Danish may occur sentence-initially, but contrasted objects are not obligatory in this position. A contrasted object can also occur in a subject-initial paraphrase, in which case the contrasted object (you) is prosodically prominent: She likes George, Paul, John, and Ringo alright, but she loves you. One difference between Danish subject-initial and object-initial sentences is that initial subjects are licensed in out-of-theblue all-focus statements, whereas initial objects are not licensed in this context. Example (3) shows licensing of an initial subject that is part of an all-focus statement, and example (4) shows that an initial object is not licensed as part of an all-focus statement.

(3) (Gæt engang hvad jeg oplevede på Penny Lane!)

En smuk sygeplejerske solgte valmuer fra en bakke.

A beautiful nurse sold poppies from a tray.

'(Guess what I just experienced in Penny Lane!)

A pretty nurse was selling poppies from a tray.'

(2) (Gæt engang hvad jeg oplevede på Penny Lane!)

?Valmuer solgte en smuk sygeplejerske fra en bakke.

Poppies sold a beautiful nurse from a tray.

'(Guess what I just experienced in Penny Lane!)

?Poppies, a pretty nurse was selling from a tray.' 


\section{Frequency, Context, and Word Order Processing}

The correlation between infrequency of object-initial clauses, processing difficulties for object-initial clauses, and increased activation of the L-IFG in Danish, as well as in other languages, leads us to speculate that there could be a causal relation between these factors. One way to model a causal relation would be to see objectinitial clauses as being more complex due to intraclausal factors, that is, because object-initial clauses involve movement, greater working memory demands and violations of the argument hierarchy, the sensation of an object-initial clause will be more difficult to process and the BOLD response in L-IFG will increase. These intraclausal factors constitute the backbone of such a model. Previous fMRI experiments have manipulated intraclausal factors to show their effects on the processing of objectinitial clauses. Bornkessel and colleagues compared German object-initial clauses in which the object was the Undergoer to a subtype of German object-initial clauses with object-experiencer verbs like (auffallen, 'notice') that, unusually for object-initial clauses, established the object as the Actor (the experiencer), thereby not violating the argument hierarchy (Bornkessel et al., 2005). Demands on working memory have been manipulated too, in a comparison of German object-initial subordinate clauses with either short or long distance between the fronted object and the subject (Fiebach et al., 2005). As for movement, the number of permuted objects within a single sentence has been manipulated (Friederici, Fiebach, Schlesewsky, Bornkessel, \& von Cramon, 2006). It could be further speculated that the processing difficulties with object-initial clauses is the cause of a typological preference for SOV and SVO orders (Kemmerer, 2012), except for in particular contexts. This is one way of imagining a causal relation.

However, there are alternative ways of modeling a causal relation, which do not only rely on intraclausal factors. One type of alternative modeling takes as its starting point the idea that humans make predictions at different levels (Kristensen \& Wallentin, in press; Friston, 2005) and that language users will continuously try to predict the nature of future linguistic input, including the argument order. Language users can base their predictions on all sources available to them, for example, genre, speaker characteristics, the frequency of the structure both in the ongoing discourse and in earlier discourse, verb restrictions, and the semantics and pragmatics of the context. As subject-initial clauses are generally more frequent than object-initial clauses, at least for all-focus statements, the recipient is more likely to expect a subject-initial than an object-initial clause. Under specific contextual circumstances, the recipient may expect an object-initial clause; however, even in an appropriate context, the odds for a subject-initial clause may still be higher than for an object-initial clause. When the recipient fails to correctly predict the argument order of an upcoming clause, a surprisal effect (Clark, 2013; Levy, 2008) occurs. Based on associations and analogies (Bar, 2007), the recipient predicted one type of input, but a different input occurs. This surprise requires that the recipient sets up a new prediction and/or reanalyzes the input in an increased bottom-up manner. The result of the falsified prediction is increased processing difficulties and, for this specific type of prediction error, an increased BOLD response in L-IFG. In this model the frequency of the structure, among other factors, affects the ease of processing. The idea is that the difficulty lies in the structure being less predictable, which is due to extraclausal factors, including infrequency. Predictions have most often been studied in relation to the dopamine system (e.g., Zacks, Kurby, Eisenberg, \& Haroutunian, 2011; Schultz, 2007). However, given that the brain is a hierarchical predictive system (Friston, 2005), predictions should be found at many different levels of processing. L-IFG may thus constitute another level in the predictive hierarchy than the dopaminergic system, yet still perform predictive processing.

\section{Context Affects Behavioral Measures for Word Order Processing}

The relationship between frequency of structure and word order processing difficulty, unfortunately, cannot be disentangled. The frequency of object-initial clauses in the preceding discourse can be manipulated, but the overall frequency cannot. However, the idea that processing difficulties for object-initial clauses can be manipulated by extraclausal factors (by predictive coding or by reanalysis) is testable. For instance, if L-IFG reflects linguistic prediction errors, we can use context to prompt the prediction that a certain structure is coming up and either confirm or disconfirm this prediction and observe how L-IFG is activated. Taking extraclausal factors into account, we expect that the processing patterns and the BOLD response in L-IFG change if the frequency of the structure is altered, for example, if the structure is primed (Bock, 1986) locally or globally or if it occurs in a context where the structure is more likely to appear. If the recipient has a better chance at predicting the occurrence of an object-initial clause or reanalyzing it in the light of the discourse context, the processing will be eased and the BOLD response will decrease.

The influence of extraclausal factors on the processing of object-initial clauses has already been tested in a number of behavioral experiments. For Finnish, Kaiser and Trueswell (2004) found that the discourse context had a stronger facilitating effect on decreasing the length of reading times for object-initial clauses than for subjectinitial clauses. A similar interaction between context and word order has been found for Dutch subordinate clauses (Mak, Vonk, \& Schriefers, 2008). For Danish, a reading study (Kristensen et al., 2014) found that context affected off-line measures of comprehension differently for object-initial and subject-initial sentences: An 
interaction was found for both response accuracy and RT for subsequent comprehension questions, indicating that context improves comprehension more for objectinitial clauses than for subject-initial clauses.

Both EEG studies and neuroimaging studies have shown that the discourse context can attenuate semantic anomaly effects and world knowledge anomaly effects. Hald, Steenbeek-Planting, and Hagoort (2007) found that the processing of roundabouts in the sentence The city Venice has very many roundabouts and beautiful buildings elicited an N400 world knowledge anomaly effect compared with the processing of the world knowledge compatible word canals. However, when the sentence occurred in a discourse context that discussed the recent traffic regulations in Venice, the anomaly effect was attenuated. For a similar paradigm, an fMRI study by Menenti, Petersson, Scheeringa, and Hagoort (2009) found that world knowledge anomaly effects, which triggered the activation of bilateral IFG (BA 45/47), were partly neutralized by a local discourse context. Both studies show that the discourse context affects sentence processing in the brain. However, so far, to our knowledge, no neuroimaging experiment has found an interaction between discourse context and word order, neither for Danish, nor for other languages (see Discussion section for a description of a recent null result by Kristensen et al., 2013).

\section{Predictions of the Present Study}

The present study examines the effect of discourse context on the processing of Danish subject-initial and objectinitial clauses. We compare two kinds of contrastive context: One is suitable for object-initial clauses, but pragmatically inappropriate for subject-initial clauses; the other is suitable for subject-initial clauses, but pragmatically inappropriate when preceding an object-initial clause. This means that we test for the effect of a pragmatically appropriate versus inappropriate context. As a control task, the present study also compares the differences between processing Danish subject-initial and object-initial clauses in isolation, i.e., when there is no preceding linguistic context.

The aim of our study is to test whether pragmatic appropriateness of a discourse context affects word order processing in the L-IFG — on the grounds of prediction-based models, we expect that it does. A subject-initial word order is pragmatically appropriate in all-focus statements, but an object-initial word order is inappropriate and unexpected in all-focus statements and may therefore cause prediction errors. We expect that, when processed in isolation, the processing of Danish object-initial clauses with casemarked pronouns will show a larger BOLD response in the IFG (our ROI) compared with their subject-initial counterparts. We also expect response accuracy and RTs to reflect increased efforts for object-initial clauses in this condition, that is, we expect lower response accuracy and longer RTs for object-initial clauses. More importantly, we expect that the difference between a pragmatically appropriate and a pragmatically inappropriate context will be more pronounced for object-initial clauses than for subject-initial clauses-both when it comes to response accuracy and $\mathrm{RT}$ and when it comes to the BOLD response in the IFG, that is, we expect an interaction between context and word order.

\section{METHODS}

\section{Materials}

The experiment consisted of two separate tasks: a main task and a control task. In the main task, the participants listened to subject-initial and object-initial target sentences, which were either preceded by a pragmatically appropriate or inappropriate context sentence. In the control task, the participants listened to the same target sentences, but the preceding context sentence was played in reverse, that is, the context sentence did not constitute a linguistic input and merely served as an acoustic input.

The main task was based on a $2 \times 2$ design, that is, there were two factors each with two levels: context (which contrasts the subject vs. the object of the target sentence) and word order (subject-initial vs. object-initial). Examples of the material used in the main task are shown in Table 1. In this task, the participants were each exposed to 120 trials. These 120 trials consisted of 30 trials for each of the four conditions: The SS condition (the context contrasts the subject of the target sentence, and the target has a subject-initial word order), the OS condition (the context contrasts the object, and the target has a subject-initial word order), the OO condition (the context contrasts the object, and the target has a subject-initial word order), and the SO condition (the context contrasts the subject, and the target has an object-initial word order). The SS and OO conditions thus each had an appropriate context. In both these conditions, the contrasted element of the context sentence referred to the same entity (male or female) as was contrasted in the target sentence by means of fronting and prosodic prominence. In the SS examples of Table 1, both context and target support a contrastive interpretation of the male entity (Peter). In the OO examples, both context and target support a contrastive interpretation of the female entity (Anne). The OS and SO conditions, on the other hand, were pragmatically anomalous as the context was inappropriate for the target sentence: The element contrasted by the context referred to a different entity than the element signaled as contrast by means of the word order and prosody of the target sentence. In the OS examples, the context establishes the female entity as a contrasted element, but in the target sentence the female pronoun is neither fronted nor prosodically prominent; instead the initial pronoun (the subject) of the target sentence is prosodically prominent. In the SO examples, there is no correspondence either: The 
Table 1. Materials for the Two Tasks, Exemplified by the Target Verb Bemcerke ("Notice") with Peter as Agent and Anne as Patient

\begin{tabular}{|c|c|c|c|c|}
\hline \multirow[b]{2}{*}{ Materials for Main Task } & \multicolumn{2}{|c|}{ Subject-initial Target (S-target) } & \multicolumn{2}{|c|}{ Object-initial Target (O-target) } \\
\hline & Main Verbs Are Antonyms & Main Verbs Are Synonyms & Main Verbs Are Antonyms & Main Verbs Are Synonyms \\
\hline \multirow{4}{*}{$\begin{array}{l}\text { Context contrasts the } \\
\text { subject of the target } \\
\text { sentence (S-context) }\end{array}$} & $\begin{array}{l}\text { (SS) Alle overså Anne og hendes } \\
\text { bror-undtagen Peter. }\end{array}$ & $\begin{array}{l}\text { (SS) Ingen fik øje på Anne og } \\
\text { bendes bror-bortset fra Peter. }\end{array}$ & $\begin{array}{l}\text { ?(SO) Alle overså Anne og } \\
\text { bendes bror-undtagen Peter. }\end{array}$ & $\begin{array}{l}\text { ?(SO) Ingen fik øje på Anne og } \\
\text { bendes bror-bortset fra Peter. }\end{array}$ \\
\hline & 'Han bemoerkede hende. & 'Han bemoerkede hende. & Hende bemoerkede han. & 'Hende bemoerkede han. \\
\hline & $\begin{array}{l}\text { (SS) Everybody overlooked } \\
\text { Anne and her } \\
\text { brother-except Peter. }\end{array}$ & $\begin{array}{l}\text { (SS) Nobody caught sight of } \\
\text { Anne and her brother-apart } \\
\text { from Peter. }\end{array}$ & $\begin{array}{l}\text { ?(SO) Everybody overlooked } \\
\text { Anne and her } \\
\text { brother-except Peter. }\end{array}$ & $\begin{array}{l}\text { ?(SO) Nobody caught sight of } \\
\text { Anne and her brother-apart } \\
\text { from Peter. }\end{array}$ \\
\hline & 'He noticed her. & ‘He noticed her. & 'Her, he noticed. & 'Her, he noticed. \\
\hline \multirow[t]{4}{*}{$\begin{array}{l}\text { Context contrasts the } \\
\text { object of the target } \\
\text { sentence (O-context) }\end{array}$} & $\begin{array}{l}\text { ?(OS) Peter overså alle } \\
\quad \text { butikstyvene-undtagen Anne. }\end{array}$ & $\begin{array}{l}\text { ?(OS) Peter fik ikke øje på } \\
\quad \text { nogen af butikstyvene-bortset } \\
\text { fra Anne. }\end{array}$ & $\begin{array}{l}\text { (OO) Peter overså alle } \\
\text { butikstyvene-undtagen Anne. }\end{array}$ & $\begin{array}{l}\text { (OO) Peter fik ikke øje på } \\
\text { nogen af butikstyvene-bortset } \\
\text { fra Anne. }\end{array}$ \\
\hline & 'Han bemoerkede bende. & 'Han bemoerkede bende. & Hende bemoerkede ban. & 'Hende bemoerkede ban. \\
\hline & $\begin{array}{l}\text { ?(OS) Peter overlooked all the } \\
\text { shop lifters-except Anne. }\end{array}$ & $\begin{array}{l}\text { ?(OS) Peter did not catch } \\
\text { sight of any of the shop } \\
\text { lifters-apart from Anne. }\end{array}$ & $\begin{array}{l}\text { (OO) Peter overlooked all the } \\
\text { shop lifters-except Anne. }\end{array}$ & $\begin{array}{l}(\mathrm{OO}) \text { Peter did not catch sight of } \\
\text { any of the shop lifters-apart } \\
\text { from Anne. }\end{array}$ \\
\hline & 'He noticed her. & 'He noticed her. & ‘ Her, he noticed. & 'Her, he noticed. \\
\hline \multicolumn{5}{|l|}{ Materials for Control Task } \\
\hline \multirow{2}{*}{$\begin{array}{l}\text { Context played in reverse } \\
\text { (R-context) }\end{array}$} & \multicolumn{2}{|c|}{ (RS) (Context played reverse) 'Han bemoerkede hende. } & \multicolumn{2}{|c|}{ (RO) (Context played reverse) 'Hende bemoerkede han. } \\
\hline & \multicolumn{2}{|c|}{ (RS) (Context played reverse) 'He noticed her. } & \multicolumn{2}{|c|}{ (RO) (Context played reverse) 'Her, he noticed. } \\
\hline
\end{tabular}

In the table, target sentences are underlined, while context sentences are not. English translations are given below each example.

$=$ main sentence stress of the target sentence.

$?=$ pragmatically inappropriate combination of context sentence and target sentence. 
male entity is established as contrasted by the context, but the female pronoun, not the male one, is fronted and prosodically prominent in the target sentence.

The idea of the control task was to compare the processing of the object-initial and subject-initial target clauses without discourse context. The control task was meant to assure that the processing measures for the word order alternations of the present study would be comparable to those of previous neuroimaging studies of word order without discourse context (e.g., Ben-Shachar et al., 2004; German: Bornkessel et al., 2005). The control task used the same context and target sentences as the main task and was built on a subtraction paradigm with two conditions. In both conditions, the context sentence was played in reverse. In the RS condition, the target sentence was subject-initial, in the RO condition, the target sentence was object-initial.

Each participant was exposed to each of the 30 transitive target verbs in all six conditions: the SS, SO, OS and OO conditions in the main task and the RS and RO conditions in the control task. For variation purposes, we constructed two kinds of contexts for each of the propositions: In the antonym context, the predicate of the context and the target sentence were antonyms or near-antonyms, for example, overså ('overlooked'/'failed to notice') and bemoerkede ('noticed'). In the synonym context, the two predicates were synonyms or near-synonyms, for example, fik øje på ('caught sight of') and bemoerkede ('noticed'). In the main task, each transitive target verb appeared to half of the participants in the antonym context and to the other half in the synonym context, in such a way that, for every participant, 15 target verbs appeared only in the antonym context and the other 15 target verbs appeared only in the synonym context.

Each target sentence involved a pair consisting of a female individual and a male individual with relatively frequent Danish two syllable names. For one third of the target verbs the names were Anne and Peter, for another third of the verbs they were Mette and Kasper, and for the last third we used the names Lise and Søren. For each of the 30 transitive target verbs, we constructed contexts on the basis of two different propositions: one in which the male individual was the subject, as in Table 1 , and another in which the female individual was the subject. As an example, the female subject version of the SS condition with an antonym main verb would be the Danish version of Everybody overlooked Peter and his sister - except Anne. She noticed him.

The R-context and S-context of Table 1 are supportive of subject-initial targets. These two types of context do not provide the prerequisites for an object-initial clause. In terms of predictions, they can be seen as raising the odds for a subject-initial continuation and narrow down the recipient's expectations toward information structure: It is very likely that their continuation will be subject-initial rather than object-initial. The S-target is predicted, but the O-target is likely to provoke a prediction error.
The O-context is supportive of object-initial targets, as it provides the prerequisites for an object-initial clause (it contrasts the object of the target sentence). Compared with the S-context or the R-context, an O-context followed by an O-target is less likely to cause prediction errors. O-contexts can be continued by both subject-initial and object-initial clauses and are therefore less specific in their predictions. For the specific S-targets of this experiment, however, the information structure as a whole is pragmatically inappropriate as a continuation of the S-context, as the contrasted object of the S-target is neither fronted nor prosodically prominent.

The experiment involved 16 experimental lists. To vary the order in which conditions appeared one after another, each list was pseudorandomized. We made a mirror copy of each of these 16 lists by reversing the order of trials, resulting in 32 experimental lists, one for each participant in the study. Across the 32 experimental lists, we aimed at a perfect balance between the three types of contexts (contrasting the subject $\times$ contrasting the object $\times$ null context), the two types of target word order (subjectinitial $\times$ object-initial), the two types of context verbs (antonym $\times$ synonym), the two types of gender distribution in the target sentence (male subject $\times$ female subject), that is, there were 24 instantiations for each of the 30 target verbs. In each list, a verb occurred in 6 of these 24 combinations. They were distributed such that each list included one item for each of the six experimental conditions (SS, SO, OS, OO, RO, and RS) with three items for each of the two possible genders of the subject (male subject and female subject).

\section{Procedure}

Before the actual scanning experiment, each participant completed a short training session outside the scanner room on a pc with an attached response box. The training session consisted of two tasks. The first task contained six trials in the main task format (see Table 1 and Figure 1); the second task contained six trials in the control task format. These training tasks allowed the participant to get accustomed to the use of the response box and to the procedure of both the main task and the control task.

After completing the training session, the participant proceeded to the scanner room. After settling in the scanner bed and undergoing prescans (scout and T1weighted structural scan), the participant proceeded to the two tasks. All stimuli were presented using the Cogent 2000 toolkit (http://www.vislab.ucl.ac.uk/cogent. php) for Matlab (Mathworks, Inc., Sherborn, MA). Audio material was presented through a pair of electrodynamic headphones (MR confon, Magdeburg, Germany), which also attenuated scanner noise. Visual stimuli were projected onto a screen placed at the head of the scanner bed and viewed through a mirror mounted on the head coil.

fMRIs were acquired on a Siemens Magnetom Trio 3T MRI scanner using a 12-channel matrix head coil. Scans 
Figure 1. Procedure for main task and control task.

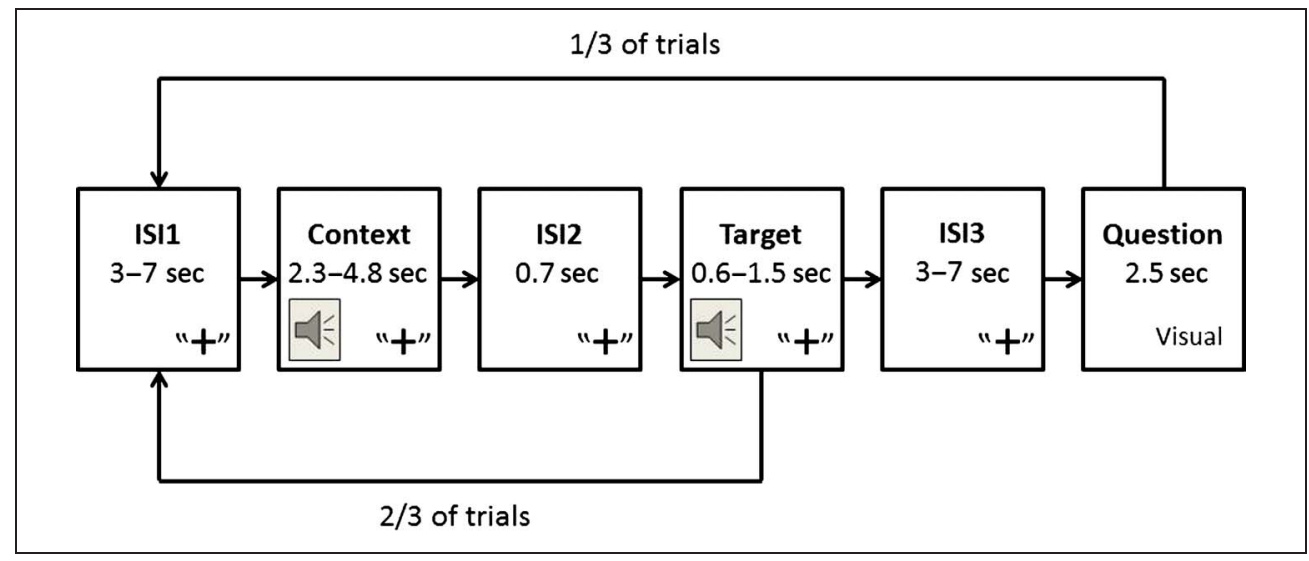

were performed using an EPI sequence with flip angle $=$ 90 , echo time $=27$ and repetition time $=2090 \mathrm{~ms}$. Each volume consisted of 42 axial slices (slice thickness $=3 \mathrm{~mm}$, spacing 0 , field of view $=192 \mathrm{~mm}$, yielding $3 \times 3 \times 3 \mathrm{~mm}$ isotropic voxels.

The participant first completed the main task, which consisted of 120 trials and lasted approximately $24 \mathrm{~min}$ (718 volumes). After a short break, the participant continued to the second task, the control task, which consisted of 60 trials and lasted approximately $12 \mathrm{~min}$ (374 volumes). Figure 1 shows the procedure for stimulus presentation for both tasks. The participant first saw a fixation cross on the screen for a time-varying interval of 3-7 sec (ISI1). With the fixation cross still displayed on the screen, the audio material was played through the head phones: first the context sentence, which lasted $2.3-4.8 \mathrm{sec}$, then a fixed ISI of $0.7 \mathrm{sec}$ (ISI2), and finally the target sentence, which lasted $0.6-1.5 \mathrm{sec}$, depending on the length of the verb.

One third of the target sentences were followed by a 3-7 sec ISI (ISI3) and a comprehension question. These question trials were randomly distributed. The question was shown visually on the screen for $3 \mathrm{sec}$ (replacing the fixation cross). The participant held a response box in the right hand and was instructed to answer "yes" by pressing a green button with the right index finger or "no" by pressing a red button with the right middle finger. The instruction was to give both fast and accurate responses. The response accuracy and the RT were logged for responses given within the 2.5-sec display period of the question.

In the main task, the comprehension questions contained the verb of the target sentence and two proper nouns referring to the subject and the object of the target sentence. For each target sentence, the participant read either a question that required a yes-response, that is, Bemoerkede Peter Anne? ('Did Peter notice Anne?') for the stimuli in Table 1, in which Peter is the agent, or a question that required a no-response, that is, Bemoerkede Anne Peter? ('Did Anne notice Peter?'), for which the semantic roles of the question were not in accordance with the target sentence. The two types of questions were balanced across trials.
The questions for the control task were similar to those of the main task, only, as the entities of in the control task were only referred to by means of pronouns (not by means of proper nouns), the questions of the control task consisted of the target sentence verb and two pronouns, that is, Bemoerkede han hende? versus Bemoerkede bun ham? ('Did he notice her?' vs. 'Did she notice him?').

\section{Participants}

Thirty-three native speakers of Danish participated in the experiment. All were right-handed and had no medical or mental history or neurological trauma. The vast majority were university students. None of the participants studied linguistics, as we preferred participants with little or no theoretical knowledge of pragmatics and word order processing. The experiment was ethically approved by The Central Denmark Region Committees on Biomedical Research Ethics, and participants all gave written consent prior to participation.

One of the 33 participants reported being fatigued and unable to concentrate well during the experiment. These conditions were reflected in a poor response accuracy rate (only 58\% correct responses), and his data were therefore excluded from further analysis. Three of the remaining 32 participants completed the main task, but not the control task.

Due to technical problems with the response box, the responses for two of the 32 participants were not registered. However, these two participants reported being concentrated during the scanning, and their neuroimages were therefore analyzed with the rest of the group. For another five subjects, only button presses on the NObutton were registered. As these five subjects all had a high response accuracy rate when the right answer was "no" (95\% response accuracy for the first task, 98\% response accuracy for the control task), their images were also analyzed with the rest of the group.

The exclusion of behavioral data resulted in three pools of participants. For the main task of the neuroimaging analysis, the pool of participants consisted of all 
32 participants (11 women, 21 men) with a mean age of 23.3 years (age range $=18-38$ years, $S D=3.7$ ). For the control task of the neuroimaging analysis, the pool of participants consisted of the 29 participants who had completed both the main task and the control task (mean age $=23.2$, age range $=18-38$ years, $S D=3.8$ ). For the behavioral analysis, the pool consisted of a subset of these 29 participants: 25 participants ( 8 women, 17 men) with a mean age of 23.4 years (age range $=18-38$ years, $S D=$ 4.0) for which all responses were correctly registered.

\section{Data Analysis}

The behavioral data were analyzed by means of the statistical software package R version 2.15.0 (Team, 2010). As the comprehension questions in the main task were different from and presumably more difficult than the comprehension questions of the control task, the accuracy rates and question RTs for the two tasks were analyzed separately.

The imaging data were analyzed using SPM8 (Statistical Parametric Mapping, Wellcome Department of Imaging Neuroscience, University College London). Events of interest were defined as the time from the onset to the offset of the target sentences. These events were convolved with the standard hemodynamic response function in SPM8. The data for each participant were motion-corrected and realigned to the first EPI image. The images were normalized to the MNI template (Montreal Neurological Institute) using the "normalize" function in SPM and smoothed with an isotropic Gaussian kernel to account for noise and differences between participants (FWHM 10_10_10 mm).

We used these normalized and smoothed images to estimate the main effects and the interaction between them by means of a two-step general linear model approach (Penny \& Holmes, 2007; Worsley \& Friston, 1995). First, we estimated single participant effects for each condition. Low-frequency artifacts were filtered out using the SPM8 standard discrete cosine set high-pass filer (128 sec cutoff). Serial correlation was modeled using an $\operatorname{Ar}(1)$ model. The parameter estimates for target sentences were subsequently used in a second level analysis, which explored the $t$ contrasts with a significance threshold of $p<.05$, family wise error (FWE)-corrected for multiple comparisons. Similarly, we conducted an ROI analysis, with bilateral IFG as our ROI. For this purpose, we established an ROI consisting of bilateral pars opercularis, pars triangularis, and pars orbitalis in the Automated Anatomical Labeling atlas (AAL atlas; Tzourio-Mazoyer et al., 2002) of the Wake Forest University pickatlas (Maldjian, Laurienti, Kraft, \& Burdette, 2003).

\section{Follow-up Study: Web-based Survey on Acceptability of Sentence Combinations}

Previous experiments on word order variation (e.g., in Greek: Keller \& Alexopoulou, 2001) suggest that, even when the context specifically supports an object-initial target, the recipient may still rate a subject-initial target as highly acceptable. To examine whether the OO combination of our experiment is seen as more acceptable than the OS condition, we carried out a Web-based survey where native speakers of Danish rated the degree of coherence/fit between the two sentences in 24 sentence pairs $(10 \times$ OS combinations, $10 \times$ OO combinations, $2 \times$ SS fillers, and $2 \times$ SO fillers). There were two pseudorandomized lists with identical items, but a different order of presentation. Of the 30 target verbs used in the recordings of the fMRI experiment, we randomly selected 10 target verb items. For these 10 verbs, we balanced the number of antonym and synonym versions (see Table 1), as well as the number of male and female agents in the target sentences. Each verb was played in an OS version and the associated OO version. The link to the survey was spread via social networks. Sixty-four participants responded to the survey. Three of these were excluded from the analysis: Two suggested in a comment that they had misunderstood the instructions, and one reported hearing difficulties. The responses from the remaining 61 participants (mean age $=33.1$, age range $=22-67 \pm$ 9.1) were analyzed. The participants were instructed to range the fit between two sentences in a recording. They answered (the Danish equivalent of) the question "Do the two sentences fit well together?" by means of a 5-point scale with the values "No, very badly," "Quite badly," "I don't know," "Quite well," and "Yes, very well."

\section{RESULTS}

\section{Behavioral Measures}

\section{Response Accuracy}

Across conditions, the 25 participants had an individual mean response accuracy rate between 68\% and 100\%. In the control task, there were $97 \%$ accurate responses to subject-initial target sentences and 88\% accurate responses to object-initial target sentences. According to a pairwise $t$ test, which compared the percentages of correct responses for each subject, the effect of word order on response accuracy in the control task was significant $(t=-3.7623, d f=24, p>.001 * * *)$.

In the main task (which had a different type of comprehension question) the absolute rates for response accuracy were lower than for the control task. Questions following subject-initial targets had an accuracy rate of 92\%, whereas questions following object-initial targets had a lower accuracy rate, 79\%. As shown in Figure 2, the response accuracy rates for subject-initial target sentences were $91 \%$ in an appropriate context and 92\% in an inappropriate context, whereas for object-initial target sentences, the rates were $85 \%$ and $72 \%$.

For the main task, we conducted a $2 \times 2$ ANOVA with the Percentage of correct responses as dependent variable. We found a significant main effect of Word order 
Figure 2. Percentage of accurate responses per condition for the main task and the control task. The six columns show the distribution of correct responses, incorrect responses, and no response for each of the four conditions of the main task and the two conditions of the control task. The light gray part of the columns shows the percentage of accurate answers for all 25 participants. One third of the trials were followed by a question, so for each condition, there were a total of 250 responses (10 responses per participant per condition).

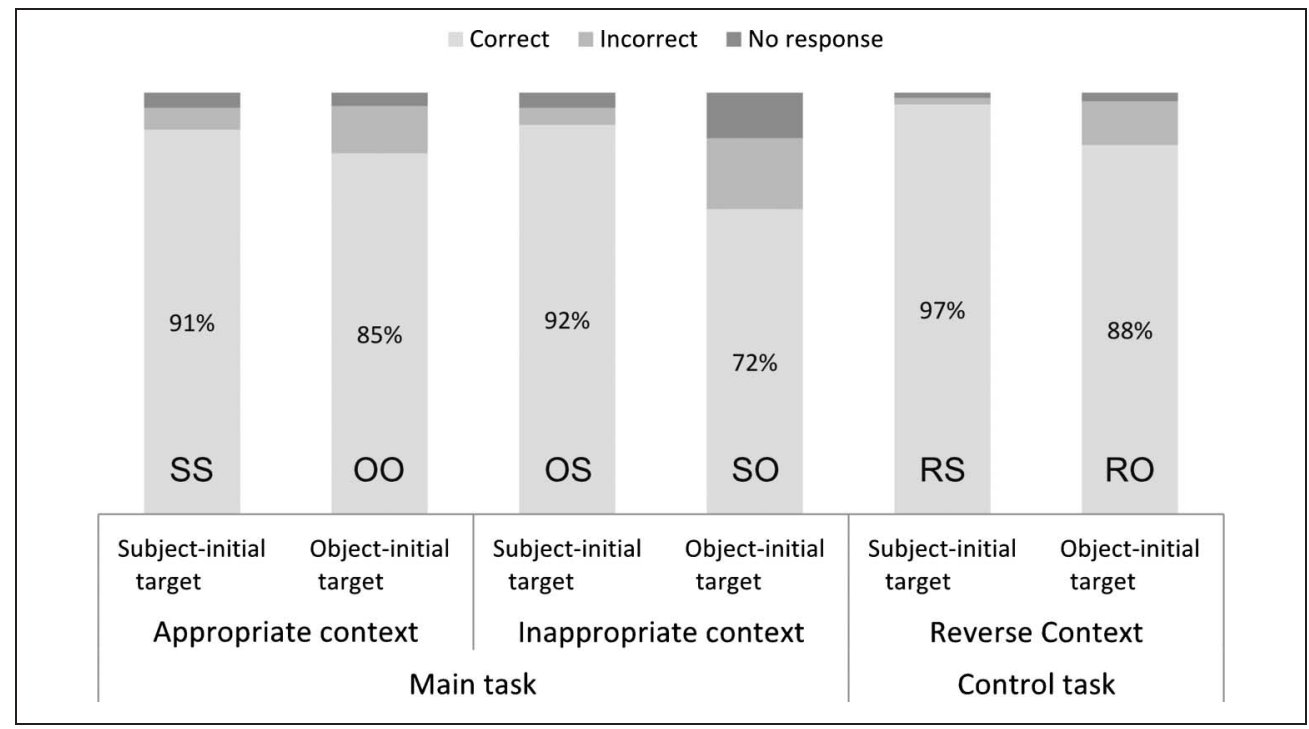

on response accuracy (by participant: $F 1(1,24)=53.02$, $p<.001^{* * *}$, by item: $\left.F 2(1,29)=25.45, p<.001 * * *\right)$, a significant main effect of Context appropriateness (F1) 1 , $\left.24)=7.579, p<.05^{*}, F 2(1,29)=8.492, p<.01^{* *}\right)$, as well as a significant interaction between Context appropriateness and Word order $\left(F 1(1,24)=7.312, p<.05^{*}, F 2\right.$ $(1,29)=8.421, p<.01 * *)$, that is, an appropriate context had a greater facilitating effect on response accuracy for object-initial target conditions (SO compared with OO) than for subject-initial target conditions (OS compared with SS). Follow-up pairwise $t$ tests show a significant difference between the SO and OO condition (by subject percentage of accurate responses: $t=-3.2755, d f=$ $24, p<.01^{* *}$; by item: $t=-3.2768, d f=29, p<$ $\left..01^{* *}\right)$. In Figure 2 , the response accuracy rate also seems slighter higher for the OS condition compared with the SS condition. According to a follow-up pairwise $t$ test, there is, nonetheless, no significant difference between the OS and SS conditions.

\section{$R T$}

We only examined the RT of correct responses. For each of the four conditions, we removed outliers above or below two standard deviations from the mean RT of each individual participant. Similarly, for the two conditions of the control task, we removed outliers above or below two standard deviations from the mean RT of each individual participant. For both tasks, we logarithmically transformed all RTs before further analyses.

In the control task (Figure 3), the mean RT for objectinitial targets was slightly longer than the mean RT for subject-initial targets (Figure 3). However, according to
Figure 3. Mean question RTs (excluding outliers) for the main task and the control task. Standard deviations $( \pm)$ are shown after the mean RT for each condition.

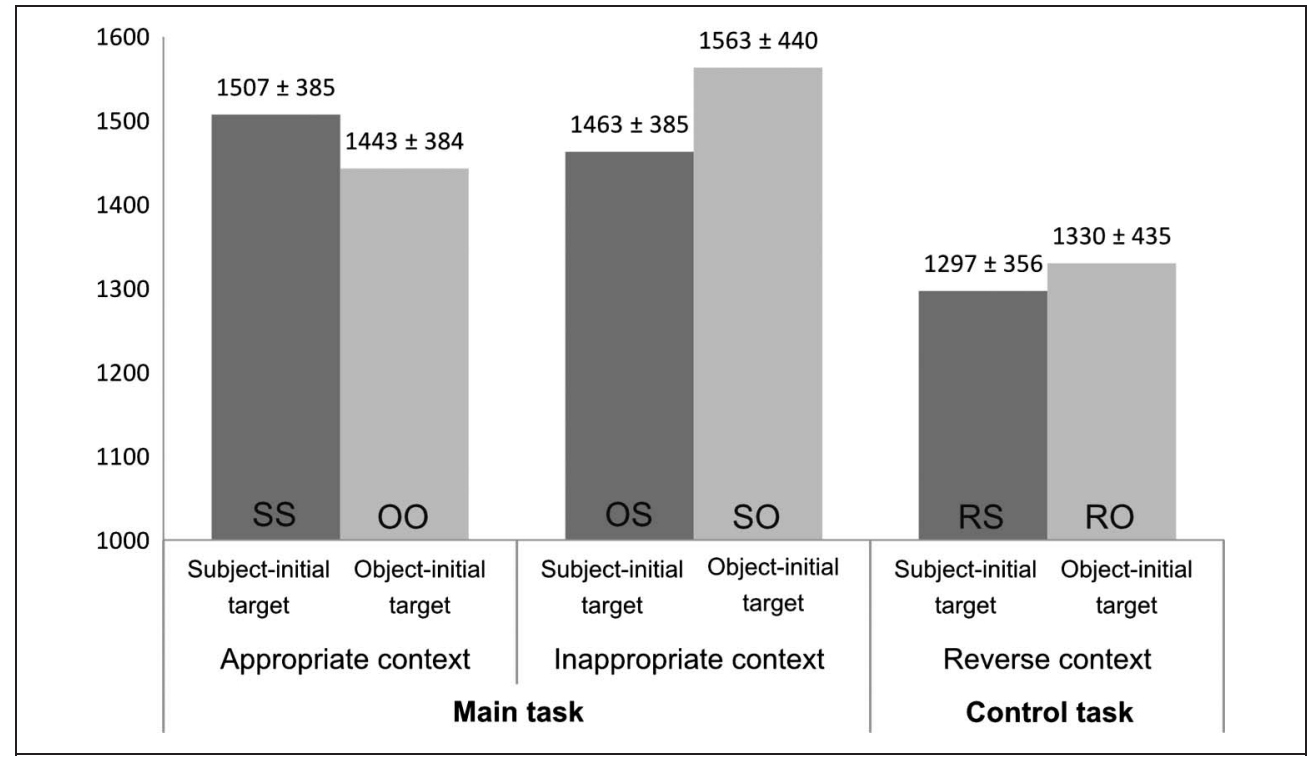


Table 2. Whole-brain Results for the Control Task (A-B) and the Main Task (C-D)

\begin{tabular}{|c|c|c|c|c|}
\hline Region & Hemisphere & Peak Z Score & Cluster Size & Peak MNI \\
\hline \multicolumn{5}{|c|}{ A. Control Task. Main Effect of Word Order: RO > RS } \\
\hline IFG (pars tri.) & Left & 5.02 & 19 & $-50,18,22$ \\
\hline \multicolumn{5}{|c|}{ B. Control Task. Main Effect of Word Order: RS $>$ RO } \\
\hline Medial frontal gyrus (gyrus rectus) & Right & 4.76 & 1 & $6,28,-16$ \\
\hline \multicolumn{5}{|c|}{ C. Main Task. Main Effect of Word Order: $S O+O O>O S+S S$} \\
\hline SMA & Middle & 4.80 & 6 & $0,18,44$ \\
\hline Cerebelum (crus 1) & Left & 4.78 & 2 & $-14,-74,-28$ \\
\hline IFG (pars orb.) & Right & 4.78 & 10 & $32,28,-6$ \\
\hline \multicolumn{5}{|c|}{ D. Main Task. Main Effect of Context Appropriateness: $\mathrm{SO}+\mathrm{OS}>\mathrm{SS}+\mathrm{OO}$} \\
\hline IFG (pars oper.) & Left & 5.20 & 21 & $-54,14,22$ \\
\hline Superior temporal gyrus & Left & 4.75 & 3 & $-66,-40,10$ \\
\hline
\end{tabular}

The table reports all clusters above threshold for one sample $t$ tests, $p<.05$ FWE-corrected for main effects and interactions. The labeling of putative anatomical regions is based on the AAL atlas.

a $t$ test, word order had no significant effect on the RT $(t=-0.3732, d f=428.416, p<.7092)$.

The results of the main task were analyzed by means of a $2 \times 2$ ANOVA. For the main task, we found no main effect of an appropriate context on RT $(F 1(1,24)=$ $0.902, n s, F 2(1,29)=1.003, n s)$ and no main effect of word order on RT $(F 1(1,24)=4.098, p>.42, F 2(1,29)=$ $0.816, n s)$. As expected, we found a significant interaction between word order and context appropriateness (F1) 1 , $\left.24)=11.05, p>.01^{* *}, F 2(1,29)=3.456, p>.073\right)$, that is, the effect of an appropriate context was bigger between the two object-initial conditions (OO and SO) than between the two subject-initial conditions (SS and OS). In fact, for subject-initial sentences, the mean RT was shorter in the inappropriate context (Figure 3), although not significantly shorter, according to pairwise $t$ tests of the average RT by item and by subject $(p>.05)$. The pairwise $t$ tests only showed significant differences for a comparison of the SO and OO condition (by subject: $t=$ 3.5702, $d f=24, p<.01 * *$; by item: $t=1.7406, d f=29$, $p<.05 *)$.

\section{Neuroimaging Data}

Whole-brain Results

Table 2 reports the whole-brain activation effects for both tasks. As for the control task, object-initial clauses showed a greater BOLD response than subject-initial clauses in the L-IFG, specifically the pars triangularis (Table 2A). Unexpectedly, for the opposite direction ( $R S>R O$ ), we found a single voxel activation above threshold in the right medial frontal gyrus (Table 2B).
In the main task, we also found a main effect of Word order (Table 2C). For object-initial target clauses (in the SO and OO conditions) compared with subject-initial clauses (SS and OS), there was more activation in the right IFG (pars orbitalis) in the SMA and in the left part of cerebellum.

We found a main effect of Context appropriateness, as shown in Table 2D. With an inappropriate combination of context and target (OS and SO) compared with an appropriate combination (SS and $\mathrm{OO}$ ), we found a larger BOLD response during the target period in the L-IFG (pars opercularis) and in a small cluster peaking in the left superior temporal gyrus, a region sometimes referred to as Wernicke's region (e.g., Bogen \& Bogen, 1976). The whole-brain analysis showed no interaction between context appropriateness and word order.

\section{ROI: IFG}

As our hypothesis was concerned with the IFG, we conducted an analysis with bilateral IFG as our ROI. The suprathreshold clusters of our ROI analysis are visualized in Figure 4, and the size and peaks of the clusters are reported in Table 3 .

In the control task, a large cluster in the L-IFG was activated more for object-initial clauses than for subjectinitial ones (Table 3A), peaking in the same area of the left pars triangularis as reported for the whole-brain results.

In the main task, we both found effects of Word order (SO \& OO > OS \& SS), of Context appropriateness (SO \& OS $>$ SS \& OO), and of the interaction between Word order and Context appropriateness (SO \& SS > OS \& 
OO). For the two conditions with object-initial clauses (OO and SO), there was more activation in the left portion of the pars opercularis and the right portion of the pars orbitalis, than for conditions with subject-initial clauses (SS and OS). As in the whole-brain analysis, the effect of an inappropriate context (SO \& OS) compared with an appropriate one (SS \& OO) peaked in the pars opercularis of the L-IFG, this time with additional activation of clusters in the right IFG (pars triangularis). The interaction between context appropriateness and word order showed a greater BOLD response in the left portions of pars opercularis and pars triangularis during targets, whose preceding context contrasted the subject of the target sentence (SS and SO) rather than the object (OS and OO).

Using the ImCalc-function of SPM, we examined whether there were overlaps between the clusters reported in Table 3. The effect of word order in the main task (Table 3B) did not overlap with any of the other clusters, but the left hemispherical pars triangularis clusters reported in Table 3A, Table 3C, and Table 3D all overlapped, that is, there was an overlap between the effect of word order in the control task, the effect of context appropriateness, and the interaction effect of the

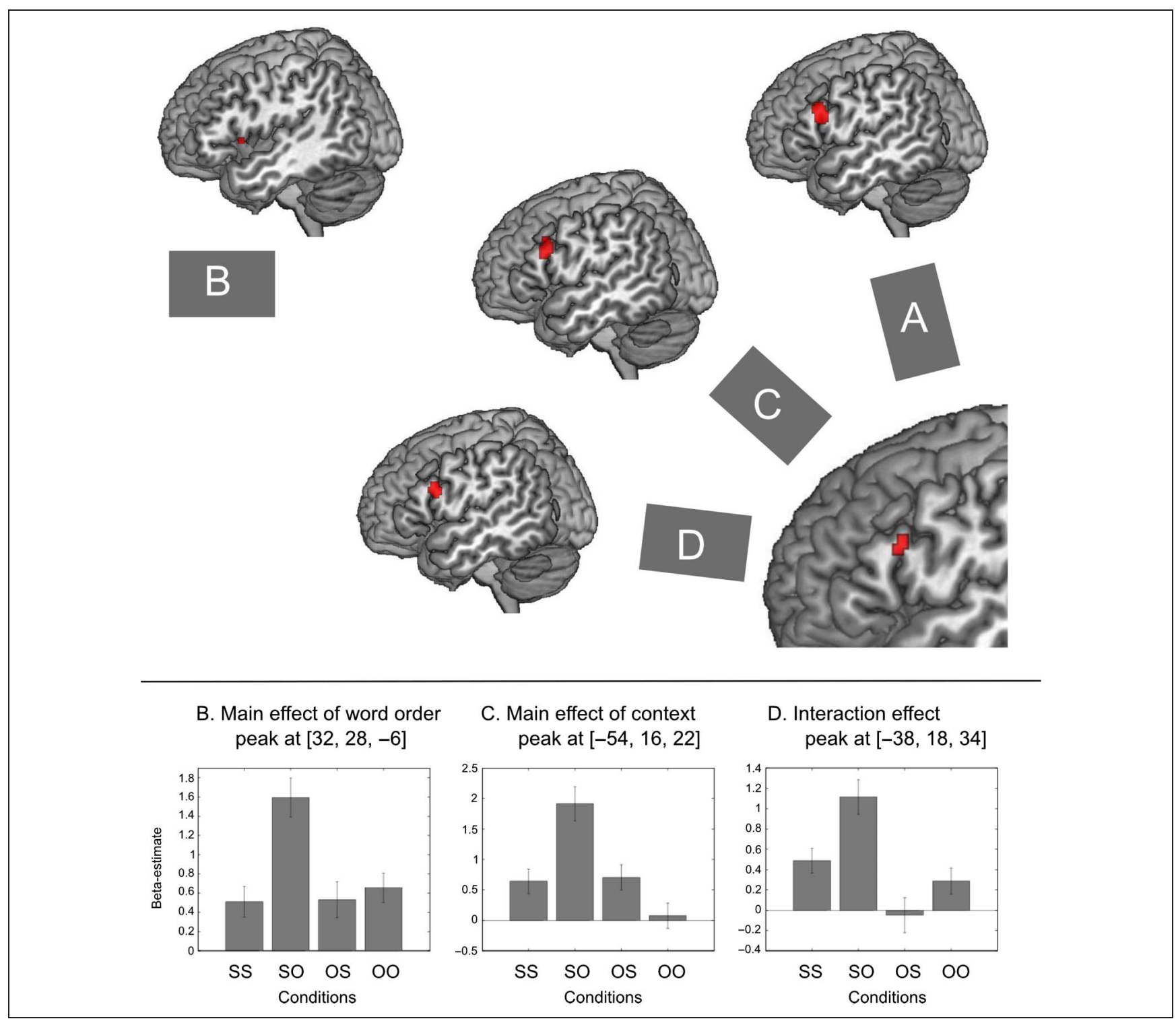

Figure 4. Surface renderings of ROI (left hemisphere). Above the horizontal line, the figure shows: (A) the main effect of word order in the control task, (B) the main effect of word order in the main task, (C) the main effect of context appropriateness, and (D) the interaction between context appropriateness and word order. The brain region in the bottom right corner shows the overlap between $\mathrm{A}, \mathrm{C}$, and $\mathrm{D}$. The images have been made using MRIcron (Rorden, 2010) and have been sliced sagitally close to the peak of activated left-lateralized clusters. Below the horizontal line, the figure shows barplots with beta-estimates for the four conditions of the main task. Barplot (B) reports the beta-estimate for the main effect of word order in the peak [32,28,-6], barplot (C) for the main effect of context appropriateness in the peak [-54, 16, 22] and barplot (D) for the interaction effect between context appropriateness and word order in the peak $[-38,18,34]$. 
Table 3. ROI Results for the Control Task (A) and the Main Task (B-D)

\begin{tabular}{|c|c|c|c|c|}
\hline Region & Hemisphere & Peak Z Score & Cluster Size & Peak MNI \\
\hline \multicolumn{5}{|c|}{ A. Control Task. Main Effect of Word Order: RO > RS } \\
\hline IFG (pars tri.) & Left & 5.02 & 171 & $-50,18,22$ \\
\hline \multicolumn{5}{|c|}{ B. Main Task. Main Effect of Word Order: $S O+O O>O S+S S$} \\
\hline IFG (pars orb.) & Right & 4.78 & 38 & $32,28,-6$ \\
\hline IFG (pars oper.) & Left & 4.37 & 10 & $-48,12,0$ \\
\hline \multicolumn{5}{|c|}{ C. Main Task. Main Effect of Context Appropriateness: $\mathrm{SO}+\mathrm{OS}>\mathrm{SS}+\mathrm{OO}$} \\
\hline IFG (pars oper.) & Left & 5.20 & 113 & $-54,16,22$ \\
\hline IFG (pars tri.) & Right & 4.49 & 67 & $48,20,22$ \\
\hline IFG (pars tri.) & Right & 4.22 & & $56,22,20$ \\
\hline \multicolumn{5}{|c|}{ D. Main Task. Interaction between Context Appropriateness and Word Order: $\mathrm{SO}+\mathrm{SS}>\mathrm{OS}+\mathrm{OO}$} \\
\hline IFG (pars oper.) & Left & 4.38 & 4 & $-38,18,34$ \\
\hline IFG (pars tri.) & Left & 4.35 & 91 & $-54,22,26$ \\
\hline
\end{tabular}

The ROI consists of bilateral IFG, defined as pars opercularis, pars triangularis, and pars orbitalis in the AAL atlas of the Wake Forest University pickatlas. The table reports all clusters above threshold $(p<.05$ FWE-corrected for multiple comparisons) for one sample $t$ tests for main effects and interactions. The labeling of putative anatomical regions is based on the AAL atlas.

main task. Figure 4 displays the activations and shows the pars triangularis overlap.

Using the plot function in SPM, we extracted the peak voxel values from first-level beta-images in the main task in order to create a barplot with the four conditions for each of the main effect of word order, main effect of context appropriateness, and the interaction effect. The results are shown in Figure 4 and demonstrate a small difference between OS and SS for all three effects and a large difference between $\mathrm{SO}$ and $\mathrm{OO}$ for all three.

\section{Follow-up Survey}

The participants in the Web-based survey (see Methods section for details) indicated whether a subset of the OO and SO pairs "fit well together" by means of a 5-point scale with the values "No, very badly," "Quite badly," "I don't know," "Quite well," and "Yes, very well." A byparticipant comparison of the ratings for the OO and SO conditions revealed that the average rating of items in the OO conditions ( 4.8 points \pm 0.3 ) was approaching ceiling, that is, considered a very good fit. The rating of $\mathrm{OO}$ items was 1.4 points better than the rating of items in the SO condition (3.4 points \pm 0.9 ) - only 2 of the 61 participants rated items in the two conditions as equally good, and one participant rated items in the OO condition as 0.2 points more negative than those in the SO condition. A pairwise $t$ test comparing each participant's mean rating of the $\mathrm{OO}$ and $\mathrm{OS}$ version showed a significant difference - the OO versions were rated as better fits ( $t=$ 9.71, $\left.d f=60, p<.001^{* * *}\right)$.

\section{DISCUSSION}

As hypothesized and predicted by an acceptability judgment experiment, the present study found an interaction between discourse context appropriateness and word order for both response accuracy, RT and the BOLD response of the L-IFG. For all three measures, an appropriate discourse context had a larger effect on the processing of object-initial clauses than on the processing of subjectinitial clauses.

\section{Processing out of a Discourse Context}

As mentioned, the single-sentence control task and the two-sentence main task vary in their level of difficulty. The control task always occurred as the second task of the two, so the participants were more used to the task format during the control task than during the main task. Also, the main task involved questions with proper nouns, for example, Bemoerkede Peter Anne?, which involved seeing the pronouns in the target sentence as having the same reference as the proper nouns of the context sentence and the question, whereas the control task involved somewhat simpler questions, which used the same verb and the same two pronouns in the question sentence (e.g., Bemoerkede han hende?) as in the target sentence. It is therefore unsurprising that the mean 
response accuracy rates appear higher for the control task than for the main task, and mean RT appears shortereven shorter than the main task conditions with an appropriate context. Giving a response in the control task was easier, although the target sentences may have been more difficult to process without a discourse context.

In the whole-brain analysis, the effect of word order in the control task peaks in the left pars triangularis, that is, in the traditional syntax area consisting of pars opercularis and pars triangularis of the L-IFG. This area corresponds to the left $\mathrm{BA} 44 / 45$, which has been found to be word order sensitive in a number of studies both for Danish (object-initial wh-questions vs. subject-beforeobject yes/no-questions: Christensen, 2008; locative alternation: Christensen \& Wallentin, 2011; object-initial vs. subject-initial sentences: Kristensen et al., 2013) and for other languages (Hebrew: Ben-Shachar et al., 2004; German: Bornkessel et al., 2005; review: Grodzinsky \& Santi, 2008). This area is traditionally associated with syntactic alternation and more recently with sensitivity to argument hierarchies and also linguistic working memory (Wallentin, Roepstorff, Glover, \& Burgess, 2006). However, the results of our main task indicate that this area is not just affected by such intraclausal factor but also when the argument order is pragmatically inappropriate. In the control task, the object-initial word order was more pragmatically inappropriate than the subject-initial one, as Danish object-initial sentences are not licensed in allfocus statements.

The whole-brain analysis for the control task also showed an unexpected one-voxel cluster in the medial frontal gyrus for subject-initial clauses compared with object-initial clauses. This minimal cluster might be attributed to the default network, which, in comparisons between two tasks, tends to be relatively more stimulated during the easier task (Gusnard \& Raichle, 2001; Shulman et al., 1997).

\section{Processing in a Discourse Context}

In the main task, the whole-brain analysis showed a main effect of Word order in the middle SMA, the left cerebellum, as well as the right IFG (pars orbitalis). As this right hemispherical activity is only found for the word order alternation in the main task, we suggest that it may be driven by the SO condition, which shows the highest BOLD response according to barplot (A) of Figure 4. In this condition, the processing seemed particularly affected by an inappropriate context, so the cluster may reflect increased discourse complexity for the object-initial clauses as known from Menenti et al. (2009), where a discourse context attenuated world knowledge anomaly effects in the right BA 45/47, and from Kuperberg, Lakshmanan, Caplan, and Holcomb (2006), who found that activation in bilateral BA 45/47 was modulated by the degree of coherence between sentences. As for the activation in the middle SMA, this cluster may reflect increased demands for re- sponse selection for the object-initial clauses (Corbetta \& Shulman, 2002; Braver, Barch, Gray, Molfese, \& Snyder, 2001).

The main effect of Word order for the main task did not overlap with the effect found in the control task (possibly due to context integration differences), but it overlapped with the traditional left hemisphere syntax area of BA 44/45, with a peak in pars opercularis (BA 44). In both the main task and the control task, we see a clear effect of word order on response accuracy and on the BOLD response of the L-IFG. However, because the main effect in the main task seems to be driven by the SO condition, we take this together with the control task to indicate that, without an appropriate discourse context, object-initial clauses were more difficult to process than subject-initial ones.

For the whole-brain analysis, an inappropriate context (SO or OS) showed a larger BOLD response in the L-IFG (pars opercularis) and the left superior temporal gyrus than an appropriate context (SS or OO). The activation in the superior temporal region may reflect increased processing demands for morphological information (Bornkessel et al., 2005). The SO and OS conditions may illustrate a conflict between the discourse-based predictions of the morphological case-marking and what appeared in the actual target. In the actual target sentence, the distribution of morphological case-marking (nominative vs. accusative) between the two noun phrases was the opposite of what was cued by the discourse context. The morphological information of the target sentence can therefore be seen as causing a surprisal effect the inappropriate context conditions. The ROI analysis showed bilateral clusters in the IFG. In the left hemisphere, the activation peaked in the pars opercularis, overlapping with the effect of word order in the control task. In the right hemisphere, it peaked in the pars triangularis, which, as mentioned, may indicate discourse-level complexity.

The main effect of Context in our ROI, which overlaps with the main effect of Word order in the control task, seems to be driven by the large BOLD response in the SO condition. As we hypothesized, a pragmatically appropriate context had a stronger facilitating effect on the processing of object-initial clauses than on the processing of subject-initial clauses: The difference between the SO and $\mathrm{OO}$ conditions was greater than the difference between the OS and SS conditions. Because of the big difference between the BOLD response for SO and OO, as seen in barplot (C) of Figure 4, it seems that the effect of a context that supports a contrastive interpretation of the subject (SO and SS conditions) is higher than the effect of a context supporting a contrastive interpretation of the object (OS and OO conditions). For both of the behavioral measures, we found a similar pattern: The effect of a pragmatically appropriate context was more pronounced for object-initial clauses than for subject-initial clauses.

Although the present study is the first to find an interaction in L-IFG between context and word order, it is not the first fMRI study to examine the interplay between discourse context and word order processing in Danish. 
In a recent fMRI study with written stimuli (Kristensen et al., 2013), we also manipulated the discourse context of object-initial and subject-initial clauses. We compared contrastive contexts similar to the supportive contexts of the present experiment to nonconstraining seminull contexts in which most of the text was masked (comparable to the null context of the present control task). We found a main effect of Discourse context on the left BA 47, but context left the left BA 44/45 unaffected, and there was no interaction between Context and Word order, that is, the activation of context-sensitive brain areas was not more pronounced for object-initial clauses than for subject-initial clauses. The difference in findings between the present experiment and that of Kristensen et al. (2013) can, however, be attributed to design differences. In particular, Kristensen et al. (2013) featured long intervals (several seconds) between the presentation of the context sentences and their subsequent targets. This was done in order to model the BOLD contrast of the context and targets independently. However, this design difference may have made it difficult for participants in the fMRI experiment to integrate context and target sentences (cf. Kristensen et al., 2013, for a discussion of problematic design issues). In the present experiment, the interval between context and target sentences only lasted $0.7 \mathrm{sec}$, allowing the participants to integrate the two sentences more easily.

Although the present experiment employed a specific kind of context manipulation in a specific language, we expect that the results are likely to generalize to other languages with frequency differences between objectinitial and subject-initial word order (e.g., German, Finnish, and Greek) and to other kinds of context manipulations that affect the appropriateness of word order. However, the degree to which a specific context in a specific language affects word order processing can be assumed to correlate with a number of variables, for example, the frequency of the type of context, the frequency of the types of word order compared, as well as cloze probability measures.

\section{Predicting the Speaker's Next Move}

Due to the poor temporal resolution of fMRI, our results do not reveal at what point in time word order processing is affected by discourse context. A syntax-first view would hold that the increased activation in the L-IFG for inappropriate contexts reflects reanalysis processes (e.g., Friederici, 2002). As this type of model does not specifically mention prediction-based processes, the recipient may in principle passively await incoming sentences and analyze the word order of the target sentence before trying to integrate the output of this analysis with contextual information. In the case of an inappropriate context, this contextual integration fails, and the target sentence undergoes reanalysis, resulting in increased activation of the L-IFG. While this syntax-first reanalysis interpretation of our data is possible, the results are also compatible with the idea that context and frequency affects the recipient's prediction of word order. In the psycholinguistics community, the concept of prediction has traditionally had a somewhat negative flavor and has primarily been associated with "undesirable strategic processing afforded by ill-designed stimuli" (van Berkum, Brown, Zwitserlood, Kooijman, \& Hagoort, 2005, p. 444). In recent years, however, prediction-based approaches are gaining ground in the psycholinguistic community (van Berkum, 2010; Levy, 2008; Federmeier, 2007). A prediction-based interpretation of context/word order manipulation is parsimonious, as it is in accordance with recent ERP studies that show context-based prediction manipulations of the N400 effect (Szewczyk \& Schriefers, 2013; Lau, Holcomb, \& Kuperberg, 2012; Cowles et al., 2007), it does not require separate theories for frequency effects and priming effects in word order processing, and it points to similarities between the processes underlying word order processing and, for example, nonlinguistic visual processing (Bar, 2007). The present study can be interpreted as pointing to a link between word order prediction and the L-IFG, but the nature of the proposed link is a question for future research to model and investigate. It is, for instance, not clear whether the L-IFG generates predictions on its own or, for example, evaluates predictions generated elsewhere in the brain as has been suggested by cognitive control accounts of the L-IFG (cf. Bornkessel-Schlesewsky et al., 2012; Novick, Trueswell, \& Thompson-Schill, 2010; Thompson-Schill, Bedny, \& Goldberg, 2005). Assuming that predictions occur at different levels (Friston, 2005) and involve different brain regions, it is also an open question how predictions that engage the L-IFG should be distinguished from predictions engaging other brain regions (cf. Kristensen \& Wallentin, in press, for a discussion).

We may take the overlaps between the main effect of Context and the interaction between Context and Word order to show that the area in BA 44/45, which has traditionally been associated with word order processing, is not just sensitive to linear processing, but also to the recipients' predictions of what the linear order should be. This assumed prediction could be based on all sources available to the processing mind. The prediction can be modulated by factors both within the clause and external to the clause. The more probability the recipient distributes to one type of information structure, the stronger the prediction of this specific information structure becomes. The violation of strong predictions will result in strong prediction errors; the violation of weak predictions will result in weaker prediction errors. The main task of our study showed a significant effect of word order on both the BOLD response in our ROI and on the response accuracy-subject-initial clauses still seem to have a processing advantage over object-initial clauses. This advantage is not surprising, following a prediction approach. If we see the brain as a prediction machine (van Berkum, 2010; Bar, 2007), previous input generates factors that can predict upcoming input. The weight of 
each of these factors is based on how reliable (how noisy, certain, or uncertain) they are (Clark, 2013), and the weights are constantly updated to minimize the prediction error. Subject-initial clauses have a higher overall frequency (as shown in Danish corpus studies), and this "global priming" may contribute to the recipients' predictions, that is, distribute more probability to a subject-initial prediction. Also, the recipient may predict that the agent appears before the patient, based on a (frequency-based or non-frequency-based) preference for this order of semantic roles. Besides global priming, the subject-before-object structure was locally primed in our experiment-both the context sentences and the questions have subject-before-object word order. There are many reasons for predicting that an upcoming sentence will be subject-initial rather than objectinitial, so even in an appropriate context, based on all sources available, the recipient's odds for a subjectinitial clause may still be high. This explains why we see a relatively larger effect of context for the object-initial sentences.

\section{Conclusion}

Although the linguistic context is not the only source that may affect word order processing, our study shows that context and word order interact. Danish object-initial clauses are less frequent than subject-initial ones and only occur in specific contexts. For object-initial clauses, an appropriate context has a more pronounced facilitating effect on response accuracy and RT and on decreasing the BOLD response in the L-IFG. In light of the existing literature on contextual effects, the increased BOLD response for object-initial clauses out of a discourse context can be interpreted as reflecting discrepancy between the information structure supported by the preceding discourse context and the information structure that actually appeared. The sensitivity of the L-IFG can therefore be seen as influenced by the discourse context.

\section{Acknowledgments}

This research was supported by the Faculty of Arts, University of Copenhagen, by Center of Functionally Integrative Neuroscience, Aarhus University, and by The MindLab Grant from the Danish Ministry of Science, Technology and Innovation.

Reprint requests should be sent to Line Burholt Kristensen, Department of Scandinavian Studies and Linguistics, University of Copenhagen, Njalsgade 120, 2300 Copenhagen, Denmark, or via e-mail: burholt@hum.ku.dk, burholt@gmail.com.

\section{REFERENCES}

Bader, M., \& Häussler, J. (2010). Toward a model of grammaticality judgments. Journal of Linguistics, 46, 273-330.

Bader, M., \& Meng, M. (1999). Subject-object ambiguities in German embedded clauses. An across-the-board comparison. Journal of Psycholinguistic Research, 28, 121-143.
Bar, M. (2007). The proactive brain. Using analogies and associations to generate predictions. Trends in Cognitive Sciences, 11, 280-289.

Ben-Shachar, M., Palti, D., \& Grodzinsky, Y. (2004). Neural correlates of syntactic movement. Converging evidence from two fMRI experiments. Neuroimage, 21, 1320-1336.

Bock, J. K. (1986). Syntactic persistence in language production. Cognitive Psychology, 18, 355-387.

Bogen, J. E., \& Bogen, G. M. (1976). Wernicke's region-where is it? Annals of the New York Academy of Sciences, 280, 834-843.

Bornkessel, I., \& Schlesewsky, M. (2006). The role of contrast in the local licensing of scrambling in German: Evidence from online comprehension. Journal of Germanic Linguistics, $18,1-43$.

Bornkessel, I., Schlesewsky, M., \& Friederici, A. D. (2003). Eliciting thematic reanalysis effects. The role of syntaxindependent information during parsing. Language and Cognitive Processes, 18, 269-298.

Bornkessel, I., Zysset, S., Friederici, A. D., von Cramon, D. Y., \& Schlesewsky, M. (2005). Who did what to whom? The neural basis of argument hierarchies during language comprehension. Neuroimage, 26, 221-233.

Bornkessel-Schlesewsky, I., Grewe, T., \& Schlesewsky, M. (2012). Prominence vs. aboutness in sequencing: A functional distinction within the left inferior frontal gyrus. Brain and Language, 120, 96-107.

Bornkessel-Schlesewsky, I., \& Schlesewsky, M. (2009). The role of prominence information in the real-time comprehension of transitive constructions. A cross-linguistic approach. Language and Linguistics Compass, 3, 19-58.

Braver, T. S., Barch, D. M., Gray, J. R., Molfese, D. L., \& Snyder, A. (2001). Anterior cingulate cortex and response conflict. Effects of frequency, inhibition and errors. Cerebral Cortex, 11, 825-836.

Caplan, D., \& Waters, G. S. (1999). Verbal working memory and sentence comprehension. Behavioral and Brain Sciences, 22, 77-94.

Chafe, W. L. (1976). Givenness, contrastiveness, definiteness, subjects, topics and point of view. In C. N. Li (Ed.), Subject and topic (pp. 25-56). New York: Academic Press.

Christensen, K. R. (2008). Interfaces, syntactic movement, and neural activation. A new perspective on the implementation of language in the brain. Journal of Neurolinguistics, 21, $73-103$.

Christensen, K. R., \& Wallentin, M. (2011). The locative alternation. Distinguishing linguistic processing cost from error signals in Broca's region. Neuroimage, 56, 1622-1631.

Clark, A. (2013). Whatever next? Predictive brains, situated agents and the future of cognitive science. Behavioral and Brain Sciences, 36, 181-204.

Corbetta, M., \& Shulman, G. L. (2002). Control of goal-directed and stimulus-driven attention in the brain. Nature Reviews Neuroscience, 3, 201-215.

Cowles, H. W., Kluender, R., Kutas, M., \& Polinsky, M. (2007). Violations of information structure: An eletrophysiological study of answers to wh-questions. Brain and Language, 102, 228-242.

Erteschik-Shir, N. (2007). Information structure. The syntaxdiscourse interface. Syntax and morphology. Oxford: Oxford University Press.

Federmeier, K. D. (2007). Thinking ahead: The role and roots of prediction in language comprehension. Psychophysiology, 44, 491-505.

Ferreira, F. (2003). The misinterpretation of noncanonical sentences. Cognitive Psychology, 47, 164-203.

Fiebach, C. J., Schlesewsky, M., Lohmann, G., von Cramon, D. Y., \& Friederici, A. D. (2005). Revisiting the role of Broca's area in sentence processing. Syntactic integration versus 
syntactic working memory. Human Brain Mapping, 24 , 79-91.

Friederici, A. (2002). Towards a neural basis of auditory sentence processing. Trends in Cognitive Sciences, 6, 78-84

Friederici, A., Fiebach, C. J., Schlesewsky, M., Bornkessel, I. D., \& von Cramon, D. Y. (2006). Processing linguistic complexity and grammaticality in the left frontal cortex. Cerebral Cortex 16, 1709-1717.

Friston, K. (2005). A theory of cortical responses. Philosophical Transactions of the Royal Society, Series B, Biological Sciences, 360, 815-836.

Grodzinsky, Y., \& Santi, A. (2008). The battle for Broca's region. Trends in Cognitive Sciences, 12, 474-480.

Gusnard, D. A., \& Raichle, M. E. (2001). Searching for a baseline. Functional imaging and the resting human brain. Nature Reviews Neuroscience, 2, 685-694.

Hagoort, P. (2005). On Broca, brain, and binding. A new framework. Trends in Cognitive Sciences, 9, 416-423.

Hald, L. A., Steenbeek-Planting, E. G., \& Hagoort, P. (2007). The interaction of discourse context and world knowledge in online sentence comprehension. Evidence from the N400. Brain Research, 1146, 210-218.

Hansen, E., \& Heltoft, L. (2011). Grammatik over det Danske Sprog. Copenhagen/Det Danske Sprog- og Litteraturselskab: Syddansk Universitetsforlag.

Harder, P., \& Poulsen, S. (2001). Editing for speaking. First position, foregrounding and object fronting in Danish and English. In E. Engberg-Pedersen \& P. Harder (Eds.), Ikonicitet og Struktur (pp. 1-22). Copenhagen: Netværk for Funktionel Lingvistik, Engelsk Institut, Københavns Universitet.

Hörberg, T., Koptjevskaja-Tamm, M., \& Kallioinen, P. (2013). The neurophysiological correlate to grammatical function reanalysis in Swedish. Language and Cognitive Processes, 28, 388-416.

Hyönä, J., \& Hujanen, H. (1997). Effect of word order and case marking on sentence processing in Finnish. An eye fixation analysis. Quarterly Journal of Experimental Psychology, 50, 841-858.

Kaiser, E., \& Trueswell, J. C. (2004). The role of discourse context in the processing of a flexible word-order language. Cognition, 94, 113-147.

Keller, F., \& Alexopoulou, T. (2001). Phonology competes with syntax: Experimental evidence for the interaction of word order and accent placement in the realization of information structure. Cognition, 79, 301-372.

Kemmerer, D. (2012). The cross-linguistic prevalence of SOV and SVO word orders reflects the sequential and hierarchical representation of action in Broca's area. Language and Linguistics Compass, 6, 50-66.

Kim, J., Koizumi, M., Ikuta, N., Fukumitsu, Y., Kimura, N., Iwata, K., et al. (2009). Scrambling effects on the processing of Japanese sentences. An fMRI study. Journal of Neurolinguistics, 22, 151-166.

Kristensen, L. B. (2013). Context, you need. Experimental approaches to information structure processing. $\mathrm{PhD}$ thesis, University of Copenhagen.

Kristensen, L. B., Engberg-Pedersen, E., Nielsen, A. H., \& Wallentin, M. (2013). The influence of context on word order processing-An fMRI study. Journal of Neurolinguistics, 26, 73-88.

Kristensen, L. B., Engberg-Pedersen, E., \& Poulsen, M. (2014). Context improves comprehension of fronted objects. Journal of Psycholinguistic Research, 43, 125-140.

Kristensen, L. B., \& Wallentin, M. (in press). Putting Broca's region into context: fMRI evidence for a role in predictive language processing. In R. Willems (Ed.), Cognitive neuroscience of natural language use. Cambridge: Cambridge University Press.
Kuperberg, G. R., Lakshmanan, B. M., Caplan, D. N., \& Holcomb, P. J. (2006). Making sense of discourse. An fMRI study of causal inferencing across sentences. Neuroimage, 33, 343-361.

Lau, E. F., Holcomb, P. J., \& Kuperberg, G. R. (2012). Dissociating N400 effects of prediction from association in single-word contexts. Journal of Cognitive Neuroscience, 25, 484-502.

Levy, R. (2008). Expectation-based syntactic comprehension. Cognition, 106, 1126-1177.

Mak, W., Vonk, W., \& Schriefers, H. (2008). Discourse structure and relative clause processing. Memory \& Cognition, 36, 170-181.

Maldjian, J. A., Laurienti, P. J., Kraft, R. A., \& Burdette, J. H. (2003). An automated method for neuroanatomic and cytoarchitectonic atlas-based interrogation of fMRI data sets. Neuroimage, 19, 1233-1239.

Menenti, L., Petersson, K. M., Scheeringa, R., \& Hagoort, P. (2009). When elephants fly. Differential sensitivity of right and left inferior frontal gyri to discourse and world knowledge. Journal of Cognitive Neuroscience, 21, 2358-2368.

Novick, J. M., Trueswell, J. M., \& Thompson-Schill, S. L. (2010). Broca's area and language processing: Evidence for the cognitive control connection. Language and Linguistics Compass, 4, 906-924.

Penny, W., \& Holmes, A. P. (2007). Random effects analysis. In K. J. Friston, J. Ashburner, S. Kiebel, T. Nichols, \& W. Penny (Eds.), Statistical parametric mapping. The analysis of functional brain images (pp. 156-165). London: Academic Press.

Rorden, C. (2010). MRIcron. http://www.mccauslandcenter.sc. edu/mricro/mricron/index.html.

Schultz, W. (2007). Behavioral dopamine signals. Trends in Neurosciences, 30, 203-210.

Shulman, G. L., Fiez, J. A., Corbetta, M., Buckner, R. L., Miezin, F. M., Raichle, M. E., et al. (1997). Common blood flow changes across visual tasks. II. Decreases in cerebral cortex. Journal of Cognitive Neuroscience, 9, 648-663.

Szewczyk, J. M., \& Schriefers, H. (2013). Prediction in language comprehension beyond specific words: An ERP study on sentence comprehension in Polish. Journal of Memory and Language, 68, 297-314.

Thompson-Schill, S. L., Bedny, M., \& Goldberg, R. F. (2005). The frontal lobes and the regulation of mental activity. Current Opinion in Neurobiology, 15, 219-224.

Thomsen, D. B, \& Kristensen, L. B. (in press). Context needed: Semantic role assignment in Danish children and adults. Acta Linguistica Hafniensia, 46.

Tzourio-Mazoyer, N., Landeau, B., Papathanassiou, D., Crivello, F., Etard, O., Delcroix, N., et al. (2002). Automated anatomical labeling of activations in SPM using a macroscopic anatomical parcellation of the MNI MRI single-subject brain. Neuroimage, 15, 273-289.

van Berkum, J. (2010). The brain is a prediction machine that cares about good and bad-Any implication for neuropragmatics? Italian Journal of Linguistics, 22, 181-208. van Berkum, J. J. A., Brown, C. M., Zwitserlood, P., Kooijman, V., \& Hagoort, P. (2005). Anticipating upcoming words in discourse: Evidence from ERPs and reading times. Journal of Experimental Psychology: Learning, Memory, and Cognition, 31, 443-467.

Wallentin, M., Roepstorff, A., Glover, R., \& Burgess, N. (2006). Parallel memory systems for talking about location and age in precuneus, caudate and Broca's region. Neuroimage, 32, 1850-1864.

Worsley, K. J., \& Friston, K. J. (1995). Analysis of fMRI timeseries revisited-Again. Neuroimage, 2, 173-181.

Zacks, J. M., Kurby, C. A., Eisenberg, M. L., \& Haroutunian, N. (2011). Prediction error associated with the perceptual segmentation of naturalistic events. Journal of Cognitive Neuroscience, 23, 4057-4066. 